\title{
Retos y posibilidades de la economía colaborativa en la cuidad de Bogotá
}

\author{
Challenges and posibilities from collaborative economy in Bogota city
}

\author{
Adriana Fernanda Salazar Yaquino ${ }^{1}$ \\ https://orcid.org/0000-0003-0877-2905 \\ Ivonne Daniela Pedraza Gonzalez ${ }^{2}$ \\ https://orcid.org/0000-0002-7380-913X \\ Maria Emma Lombana Gonzalez ${ }^{3}$ \\ https://orcid.org/0000-0003-0659-2935 \\ Servicio Nacional de Aprendizaje-SENA, Colombia
}

Recibido: 15-01-2020

Aceptado: 17-04-2020

\section{Cita Recomendada}

Salazar, A., Pedraza, I. \& Lombana, M. (2020). Retos y posibilidades de la economía colaborativa en la ciudad de Bogotá. Hamut'ay 7(1), 28-47.

http://dx.doi.org/10.21503/hamu.v7i1.1907

\section{RESUMEN}

La economía colaborativa es una tendencia mundial que genera una cultura de cooperación; ya que satisface necesidades por medio del compartir, reutilizar y optimizar los recursos humanos, físicos, monetarios y medioambientales. El presente artículo tiene como objetivo mostrar un panorama de la situación actual de negocios, bajo el modelo colaborativo en la ciudad de Bogotá; con el fin de identificar, retos y posibilidades a los que estos se enfrentan; mediante la aplicación de un estudio de investigación mixto, el cual consiste en el análisis, recolección y vinculación de información cualitativa por medio de la entrevista en profundidad y datos cuantitativos recolectados a través de la aplicación de una encuesta; donde se logró evidenciar que estos negocios se ven afectados por problemas relacionados con cobertura y conectividad que se presentan en un país como Colombia. Así como también el desconocimiento que tienen los usuarios, ya que el $66 \%$ de la población encuestada indicó desconocer el termino, ignorando los beneficios que esta puede ofrecer. En cuanto a los productos y servicios de mayor frecuencia de consumo y teniendo una percepción positiva ante estos, son los relacionados con los sectores de movilidad, domicilios y educación. Además, cabe resaltar que la parte legal no es un factor determinante para la utilización y que un medio clave para la promulgación de estos negocios son las herramientas de marketing digital y social media, ya que el $67 \%$ de la población utiliza las redes sociales como principal medio para obtener información de estos.

Palabras clave: economía colaborativa, regulación, tecnología, percepción, sectores.

\footnotetext{
1 Grupo de Investigación SUOMAYA, Semillero ALEPH, SENA. Economista Universidad Surcolombiana, Esp. Tecnológica en Diseño y Desarrollo de Investigaciones de Mercado, fernandayaquino@gmail.com

2 Grupo de Investigación SUOMAYA, Semillero ALEPH, SENA. Tecnóloga en gestión hotelera, Esp. Tecnológica en Diseño y Desarrollo de Investigaciones de Mercado 09daniela.pg@gmail.com

3 Grupo de Investigación SUOMAYA, Semillero ALEPH, SENA. Instructora Gestión de Mercados, Magister Psicóloga del Consumidor mlombana@sena.edu.co
} 


\section{Abstract}

Collaborative economy is a global trend that generates a culture of cooperation; it fulfils needs by sharing, reusing and optimizing human, physical, monetary and environmental resources. The objective of this article is to show a panorama of the current situation of businesses under the collaborative model in the city of Bogotá; with the aim of identifying the challenges and possibilities that these businesses face; through the application of a mixed research study, which involves analyzing, collecting and linking of qualitative information through in-depth interviews and quantitative data collected through the application of a survey; where it was possible to demonstrate that these businesses are affected by problems related to coverage and connectivity that occur in a country like Colombia. As well as the lack of knowledge that the users have, since $66 \%$ of the population surveyed indicated that they do not know the term, ignoring the benefits that it can offer. Regarding the products and services of greater frequency of consumption and having a positive perception of these, those are those related to the sectors of mobility, ordering and education. In addition, it is also remarkable that the legal aspect is not a determining factor for the use and that a key channel for proclaiming these businesses are digital marketing tools and social media since $67 \%$ of the population use social networks as the main source to get information.

Keywords: Collaborative economy, regulation, technology, perception, sectors.

\section{INTRODUCCIÓN}

La economía colaborativa es una realidad tanto a nivel nacional como a nivel mundial; esta abarca el conocimiento abierto, el consumo, la producción y las finanzas colaborativas. Siendo su característica principal el intercambio de bienes o servicios a través de plataformas digitales o no. Según la Comisión Europea esta se refiere a modelos de negocio en los cuales se facilitan actividades mediante plataformas colaborativas, las cuales crean un mercado abierto para el uso temporal de mercancías o servicios ofrecidos a menudo por particulares (Europea, 2016).

En este sentido la economía colaborativa ha estado presente en la actividad económica del hombre desde economías poco desarrolladas o el caso de economías de intercambio puro o de trueque. Donde se produce su evolución en función del estado de desarrollo de la economía y retoma su auge a partir de la tercera revolución industrial, en la cual los servicios adquieren una gran importancia y el peso relativo de la economía colaborativa toma fuerza. Este resurgimiento en los últimos años está ligado a factores como el desarrollo del sector ser- vicios y el progreso tecnológico; siendo la Internet un factor clave dentro de este proceso. (Ordoñezde-Haro \& Torres, 2019). Sin embargo, en países como Colombia donde existen limitaciones y analfabetismo tecnológico su demanda se puede ver afectada.

Además, parte de su crecimiento se debe a la preocupación por el ambiente, ya que fomenta el segundo uso de los bienes, reutilizando los productos (Rabasco, 2016). Así como también a la desigualdad, pues este tipo de negocios pueden generar ingresos extras a partir del trabajo vía Internet (Batista-Domínguez., 2018 ). En Colombia, según estadísticas DANE (2019), para el 2018 la pobreza monetaria fue $27 \%$ y la pobreza extrema fue $7.2 \%$ del total nacional. De igual forma, los casos de éxito de este tipo de negocios se han convertido en un referente para su auge y parecen estar siendo bien percibidos y acogidos por los usuarios.

Sin embargo, a pesar de su crecimiento, se han presentado barreras entre sectores a causa de su uso, en gran parte porque existen vacíos jurídicos que conllevan a la discusión y a la problemática sobre los impuestos, competencia desleal y regu- 
lación de plataformas tecnológicas (Amaya \& Forero, 2016). Por lo cual la falta de claridad puede generar un impacto en el uso de los servicios provenientes de la economía colaborativa.

Por tanto, con el presente trabajo, se pretende determinar los retos y las posibilidades de la economía colaborativa en el consumidor bogotano, puesto que se evidencia que este tipo de economía ha venido tomando fuerza como parte de la realidad colombiana. Se efectuó una revisión bibliográfica y se utilizaron técnicas cualitativas como la entrevista en profundidad y cuantitativas como la aplicación de una encuesta mediante un muestro no probabilístico por conveniencia tipo bola de nieve. Los objetivos del estudio fueron identificar cuál es el conocimiento que tienen los bogotanos sobre los negocios de economía colaborativa, conocer la percepción y grado de confianza hacia este tipo de negocios, evidenciar la frecuencia y lugar de consumo, comprender la influencia de las Tecnologías de la Información y la Comunicación (TIC), registrar los canales de comunicación a través de los cuales se adquiere información sobre los mismos y establecer qué tanto influye la legislación y normatividad al momento de adquirir un producto o servicio proveniente de negocios de economía colaborativa.

Permitiendo de esta manera entender cómo es el funcionamiento de estos en la realidad colombiana, conocer el comportamiento de consumo de los usuarios, así como también identificar la percepción que tienen los consumidores sobre estos servicios, lo anterior con el fin de dar algunas pautas para que las empresas encuentren una herramienta útil que les permita mejorar, ofrecer una mejor experiencia a sus usuarios y puedan crecer en regiones latinoamericanas.

\section{Economía colaborativa}

La economía colaborativa es un sistema económico que hace referencia a la correlación existente entre dos o más individuos por medios digitales o no, con el fin de cubrir una necesidad, basándose en el principio de la reutilización, de compartir y de la optimización para que el consumo sea sostenible. Según Máynez \& Gutiérrez (2016), su método está relacionado usualmente con el del trueque, aunque ahora con fuertes vínculos y auxilio del ecosistema digital y/o tecnológico. Barragán et al. (2017) refieren que esta se caracteriza por la variedad de oferta, ahorro para el consumidor gracias a precios bajos, gestión de los recursos, espacios y la sostenibilidad ambiental. Además, a través de ella se suprime la desigualdad permitiendo la inclusión social y económica debido al desarrollo y transformación de pequeñas empresas y el acercamiento de los individuos con las herramientas tecnológicas. Sin embargo, en cuanto a sus desventajas se encuentra la falta de regulación, inseguridad en el consumidor con el tratamiento de datos, lo que puede llegar a generar monopolios, y que los trabajadores no cuentan con prestaciones sociales. (Buenadicha, Cañigueral \& De León, 2017).

Los fundamentos principales para el correcto funcionamiento de la economía colaborativa en primer lugar son las plataformas digitales, un factor clave, ya que gracias a estos medios tecnológicos es posible poner en contacto de manera activa a la oferta y a la demanda en tiempo real. Gracias a la economía colaborativa, en la actualidad se reducen costos, promoviendo mayor interacción social, el intercambio, el empoderamiento de los consumidores y la estructuración de comunidad y/o ciudadanía. Por lo cual, los individuos sociales, las empresas y los gobiernos han empezado a generar cambios con el fin de encontrar viabilidad para el desarrollo tanto económico como social de este tipo de negocios (Máynez \& Gutiérrez, 2016).

\section{Tipos de economía colaborativa}

Dentro de la economía colaborativa se pueden identificar cuatro modelos, cada uno de estos en función de distintas exigencias y con diversas características. El primero de estos es el consumo colaborativo, fundamentado por el intercambio, alquiler, comercio de bienes y servicios; algunas veces es de forma gratuita con recursos que ya no tenían utilidad. En segunda instancia se encuentra, el conocimiento abierto que impulsa y fomenta la propagación del conocimiento sin impedimentos legales, se basa en prácticas o herramientas abiertas, que posibilitan el desarrollo y crecimiento de una manera más eficiente (Beltran, 2018). Por otra parte, en tercer lugar encontramos la produc- 
ción colaborativa que se cimienta en la creencia y/o cultura de "hazlo tú mismo"; se impulsa bajo la divulgación tanto de proyectos como servicios que se den de manera digital; lo que aquí se ofrece también se produce. $Y$ por último se encuentra las finanzas colaborativas, donde la confianza es el fundamento principal ya que se otorgan préstamos, ahorros, microcréditos, donaciones o cualquier manera de financiación a terceros; la gente debe tener la plena seguridad de que el proyecto tendrá futuro para que pueda ser financiado, y lo característico en ello, es contar con el manejo de monedas virtuales (Medrano \& Aza, 2018).

\section{Economía colaborativa: Origen y participación mundial}

Después de la gran recesión, o mejor conocida como la crisis económica mundial que se dio durante los años 2008 y 2011; varios países se vieron afectados con una economía frágil, desempleo e incluso al borde de la quiebra (Buenadicha, Cañigueral \& De León, 2017). Se originaron distintas manifestaciones en diversas partes del mundo durante el 2011 y 2012, como principales motivos el fracaso y la injusticia del sistema económico (Máynez \& Gutiérrez, 2016). Por tal motivo una parte de la población buscó soluciones emprendedoras, innovadoras, inteligentes, integrales y sostenibles; donde buscaron renovación dinamizando la economía, generando empleo y cohesión social. Dando la oportunidad y la bienvenida a la economía colaborativa (Rodríguez, Pérez \& Svensson, 2017).

En abril del 2007 en el boletín Leisure Report fue mencionado por primera vez el termino de economía colaborativa por el asesor estratégico de negocios y analista de la industria global del fitness Ray Algar. Sin embargo, fue hasta el año 2010 donde se reconoció e identificó el término gracias al libro "What's Mine Is Yours: The Rise of Collaborative Consumption" (Lo que es mío es tuyo: el aumento del consumo colaborativo) por la escritora Rachel Botsman y por el empresario británico estadounidense Roo Rogers (citado en Durán et al., 2016). Fue así, como esta empezó a manifestarse en diferentes regiones del mundo, como se muestra en la Tabla 1 donde se refleja el crecimiento y el porcentaje de participación que ha alcanzado la economía colaborativa en estas regiones del mundo, esto de acuerdo con cifras arrojadas en 2016 por el JWT Intelligence; centro para el pensamiento proactivo (Máynez \& Gutiérrez, 2016).

\section{Tabla 1.}

Porcentaje de participación de la economía colaborativa en el mundo

\begin{tabular}{|c|c|c|c|c|c|}
\hline Región & $\begin{array}{l}\text { Amé- } \\
\text { rica } \\
\text { Latina }\end{array}$ & $\begin{array}{l}\text { América } \\
\text { del Norte } \\
\text { (EEUU Y } \\
\text { Canadá) }\end{array}$ & Asia & Europa & $\begin{array}{l}\text { Medio } \\
\text { oriente }\end{array}$ \\
\hline $\begin{array}{l}\text { Porcentaje } \\
\text { de partici- } \\
\text { pación (\%) }\end{array}$ & 70 & 52 & 78 & 52 & 70 \\
\hline
\end{tabular}

Fuente: Elaboración propia sobre la base de JWT Intelligence (2016).

Asimismo, dando una mirada global, en China, el presidente Xi Jimping se comprometió a proyectar a esta ciudad como líder de innovación tecnológica a través de la economía colaborativa (Walters, 2017); por otra parte, en México, Uber tuvo un crecimiento del $20 \%$ por semana generado por el incremento de la confianza del consumidor (Buenadicha, Cañiguera \& De León, 2017); entre tanto en Europa en poco tiempo se ha evidenciado un aumento exponencial de $13.000 €$ millones a $28.000 €$ millones entre 2013 y 2015 , producto de los negocios de economía colaborativa. De igual manera, la comisión europea identificó la importancia de este tipo de economía y crearon una agenda europea con el fin de fomentar y desarrollar responsablemente la misma (Beltrán, 2018). En Colombia esta cultura colaborativa se encuentra promovida por proyectos como Connecting The Dots que permiten el desarrollo de propuestas de economía colaborativa registradas en su plataforma o el Caribe Biz Forum que busca generar conocimiento en tendencias mundiales aplicadas dentro de este campo.

\section{Economía colaborativa: Reputación, confianza y percepción.}

El buen nombre de la economía colaborativa es de suma importancia para el éxito de esta; la confianza hoy en día es uno de los pilares principales para 
que los negocios que operen bajo este modelo económico tengan éxito. En diversos estudios, se evidencia que estamos en la era de la economía de la reputación, donde la percepción juega un papel sumamente importante, sobre todo en el ecosistema digital donde se debe construir y fortalecer dichos principios. Hoy en día, los comentarios y calificaciones de los individuos acerca de algún producto o servicio influyen sobre la decisión de compra de futuros usuarios (Máynez \& Gutiérrez, 2016).

En este sentido, para generar una percepción positiva en los consumidores frente a un bien, servicio o una marca deberá primar la calidad de este, existir un plan de marketing muy bien elaborado y generar tanta confianza y seguridad para lograr una conexión emocional con el consumidor (Ferrari, 2018). Así pues, que la percepción que se genera en los individuos de la economía colaborativa varía, incluso, puede decirse que es más aceptable para las generaciones más jóvenes que para las adultas (Rodríguez, Pérez \& Svensson, 2017).

\section{¿Y cómo influye la tecnología en la economía colaborativa?}

Como se ha mencionado, una de las herramientas principales de la economía colaborativa es la tecnología y su avance ha posibilitado el acceso y promoción de bienes y servicios. También ha revolucionado la manera de hacer negocios, lo que implica una modificación en los canales por los cuales interactúa el mercado afectando de esta manera los hábitos y necesidades de consumo, ya que actualmente se presentan bajo un modelo cooperativo de fácil acceso de los usuarios, proveedores, vendedores y todos los actores involucrados (Alfonso, 2016). En Colombia el tema aún se encuentra débil con respecto a acceso, facilidad, uso y habilidades de desarrollo de las tecnologías. De acuerdo con un informe del Índice de Desarrollo de las TIC, el país ocupa el puesto 84 de 176 países (Gómez \& Pérez, 2018).

\section{La economía colaborativa y la regulación.}

A pesar de la creciente participación de la economía colaborativa; en varios países del mundo al igual que en Colombia se han presentado dificultades en temas de regulación, lo que ha limitado la posibilidad al consumidor de acceder a esta. A pesar de ello, la mayoría de ellos reconocen esta tendencia como una oportunidad para fomentar valores como la confianza y la cooperación. Permitiendo el auge de esta en sectores como movilidad, turismo y finanzas (Sobrino \& Maudes, 2016).

Sin embargo, continúa siendo una preocupación tanto para los usuarios que evitan hacer uso de estos negocios por miedo a ser sancionados, como para los líderes de este tipo de emprendimientos, que son acusados por competencia desleal (Máynez \& Gutiérrez, 2016), ya que al sancionar o censurar la economía colaborativa podría implicar un retroceso al pasado; razón por la cual se hace necesario legislar estos negocios de manera tal que se evalúen todo tipo de repercusiones, positivas o negativas (Sarasola, 2016).

En cuanto a lo que concierne a la legislación en Colombia, se evidencia que existen contradicciones, por un lado, se han dado algunos pasos en pro de regular la economía colaborativa; sin embargo, aún no existe nada puntual respecto al tema. Tal es el caso del proyecto de Ley No. 002 de 2016 del Senado cuyo fin era promover, defender y divulgar la economía colaborativa mediante la prestación de servicios de igual a igual al realizar la inscripción en el registro mercantil. A pesar de ello, este proyecto de ley no avanzó lo suficiente, y mientras que el Ministerio de Comercio Industria y Turismo proyecta legalizar Airbnb, otros ministerios como el de transporte siguen castigando con sanciones a conductores de Uber o Cabify (Cámara Colombiana de Comercio Electrónico, 2019).

Dejando entre ver falta de claridad en las normas que regulan las relaciones comerciales que tienen estos negocios, ya que las que existen son normas dispersas y con poca aplicación siendo entonces la ausencia de normatividad uno de los grandes obstáculos de la economía colaborativa, pues no permite su completo desarrollo y limita su funcionalidad (Quintero, 2018). 


\section{MATERIALES Y MÉTODOS}

\section{Participantes}

Para el estudio se utilizó un tipo de investigación mixta por tanto se combinó la información de carácter cuantitativo (encuestas) con información cualitativa (entrevistas en profundidad). En este sentido la muestra cuantitativa estuvo compuesta por un total de 267 personas residentes de la cuidad de Bogotá en edades que iban desde los 18 a los 60 años y que habían utilizado negocios de economía colaborativa; siendo el $48,6 \%$ de la población encuestada de sexo femenino y el $51,4 \%$ de sexo masculino. El proceso de muestreo corresponde a un muestreo no probabilístico dada la amplitud y características poblacionales de la cuidad de Bogotá lugar de aplicación del estudio. Esto debido a que el muestreo no probabilístico permite seleccionar aquellos casos accesibles que acepten ser incluidos y está fundamentado en la conveniencia, accesibilidad y proximidad de los sujetos (Hernández, Fernández, \& Baptista, 2014) cuyo análisis corresponde a la interpretación de la base de datos (Anexo 1) obtenida de manera descriptivita utilizando el software SPSS.

Por otra parte al utilizar la técnica de recolección cualitativa fundamentada en la entrevista en profundidad se obtuvo una "interpretación" de la realidad social, las costumbres, las ideologías, los valores (Taylor \& Bogdan, 2000) y demás aspectos relacionados con los negocios de economía colaborativa, a partir de un discurso subjetivo y la conversación directa e individual aplicada a 5 expertos en el tema de economía colaborativa, junto con 10 consumidores de estos negocios, seleccionados de acuerdo al conocimiento y uso de negocios de economía colaborativa y cuya interpretación y análisis se realizó mediante una matriz (Anexo 2), en la cual se reconoce en conjunto los aportes de los participantes y no se hace énfasis en los datos mencionados por alguien en particular, obteniendo de esta manera una visión más cercana a la realidad, enriqueciendo la información y facilitando la consecución de los objetivos propuestos.

El tipo de muestreo fue no probabilístico bola de nieve y a conveniencia, conformado por cinco expertos y diez consumidores de la categoría de pro- ductos, bajo el modelo de la economía colaborativa y para la fase cuantitativa la muestra fue de 267 personas residentes de la ciudad de Bogotá entre los 18 a 60 años de todos los estratos (Figura 1).

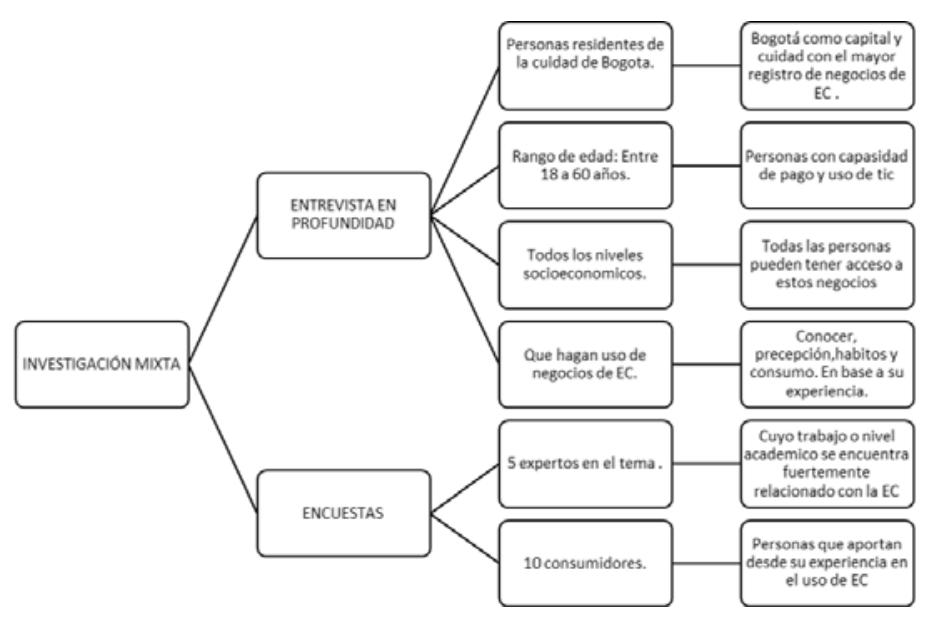

Figura 1.

Características de los participantes por método

Fuente: Elaboración propia (2020)

\section{Instrumento}

Para el desarrollo de la investigación se utilizaron dos instrumentos apoyados bajo la metodología de investigación cualitativa y cuantitativa. Con el fin de cumplir con los objetivos propuestos y dar mayor validez y confiabilidad al estudio, los cuales se presentan en la Tabla 2.

\section{Tabla 2.}

Instrumentos de recolección de información.

Planteamiento de Objetivos como herramienta primaria para elaboración de:

Entrevista en profundidad: Encuestas

Como herramienta cualitativa Como herramienta cuantitativa de recolecde conocimiento en primera instancia de percepción, uso, legalidad, conocimiento y TIC de los negocios de economía colaborativa (Anexo 3)

\begin{tabular}{|c|c|c|c|}
\hline $\begin{array}{l}\text { Método utili- } \\
\text { zado }\end{array}$ & $\begin{array}{l}\text { Criterio de } \\
\text { selección }\end{array}$ & Método utilizado & $\begin{array}{l}\text { Criterio de } \\
\text { selección }\end{array}$ \\
\hline $\begin{array}{l}\text { 1) Planteamien- } \\
\text { to de pregun- } \\
\text { tas, abiertas } \\
\text { flexibles, no } \\
\text { direccionadas }\end{array}$ & $\begin{array}{l}\text { 8) } 2 \text { grupos } \\
\text { objetivos } \\
\text { selecciona- } \\
\text { dos: } \\
\text { 9) Por el }\end{array}$ & $\begin{array}{l}\text { 12) El cuestionario consta } \\
\text { de } 21 \text { preguntas, divididas } \\
\text { en tres fases en la primera } \\
\text { fase se encuentran } 2 \text { pre- } \\
\text { guntas filtro relacionadas }\end{array}$ & $\begin{array}{l}\text { 17) Mediante } \\
\text { un muestreo } \\
\text { no proba- } \\
\text { bilístico por } \\
\text { conveniencia }\end{array}$ \\
\hline
\end{tabular}




\begin{tabular}{|c|c|c|c|}
\hline $\begin{array}{l}\text { Método utili- } \\
\text { zado }\end{array}$ & $\begin{array}{l}\text { Criterio de } \\
\text { selección }\end{array}$ & Método utilizado & $\begin{array}{l}\text { Criterio de } \\
\text { selección }\end{array}$ \\
\hline $\begin{array}{l}\text { 2) Prueba piloto } \\
\text { 3) Preparación } \\
\text { grupo objetivo } \\
\text { 4) Contacto con } \\
\text { el entrevistado } \\
\text { 5) Grabación } \\
\text { entrevista } \\
\text { 6) Trascripción } \\
\text { literal de los } \\
\text { comentarios y } \\
\text { opiniones de } \\
\text { los entrevis- } \\
\text { tados } \\
\text { 7) Análisis } \\
\text { mediante Matriz }\end{array}$ & $\begin{array}{l}\text { conoci- } \\
\text { miento que } \\
\text { poseen de } \\
\text { nego- } \\
\text { cios de } \\
\text { economía } \\
\text { colabora- } \\
\text { tiva. } \\
\text { 10) Por } \\
\text { uso de ne- } \\
\text { gocios de } \\
\text { economía } \\
\text { colabora- } \\
\text { tiva. } \\
\text { 11) Se } \\
\text { siguió una } \\
\text { misma } \\
\text { línea } \\
\text { temática }\end{array}$ & $\begin{array}{l}\text { con el uso y lugar de } \\
\text { residencia. En la segunda } \\
\text { fase se tocan puntos como } \\
\text { la percepción, uso, cono- } \\
\text { cimiento, inconveniente, } \\
\text { limitantes en relación con } \\
\text { la EC utilizando preguntas } \\
\text { abiertas de escala de } \\
\text { Likert, dicotómicas de or- } \\
\text { denar. Y en la tercera fase } \\
\text { encontramos los datos } \\
\text { demográficos relacionados } \\
\text { con ocupación, genero, } \\
\text { edad y estado civil. } \\
\text { 13) Realización prueba } \\
\text { piloto } \\
\text { 14) Trabajo en campo } \\
\text { (envió de instrumento } \\
\text { vía medios electrónicos, } \\
\text { referidos, voz a voz) } \\
\text { 15) Organización codifica- } \\
\text { ción de preguntas } \\
\text { 16) Análisis de la infor- } \\
\text { mación }\end{array}$ & $\begin{array}{l}\text { tipo bola de } \\
\text { nieve, basado } \\
\text { en: } \\
\text { a) Lugar de } \\
\text { residencia } \\
\text { (Bogotá) } \\
\text { b) rango de } \\
\text { edad, entre } \\
18 \text { a } 60 \text { años) } \\
\text { c) Uso de } \\
\text { negocios de } \\
\text { economía } \\
\text { colaborativa }\end{array}$ \\
\hline
\end{tabular}

Fuente: Elaboración propia (2020)

\section{Tipo y Diseńo}

El método de estudio utilizado para la presente investigación consiste en una investigación de carácter mixto la cual, según Hernández, Fernández \& Baptista, (2014) hacen referencia a que la meta de esta no es remplazar la investigación cuantitativa ni la investigación cualitativa, sino utilizar las fortalezas de ambos tipos de indagación; combinándolas, buscando de esta manera minimizar sus debilidades. Lo que implicó la recolección y análisis de datos tanto cuantitativos como cualitativos, así como su integración y discusión conjunta, con el fin de lograr un mayor rendimiento del fenómeno de estudio se realizaron inferencias de toda la información recabada. Por tanto, al utilizar la encuesta y entrevista en profundidad se da cumplimiento a este método adoptando ambas técnicas en el análisis y procesamiento conjunto de la información, siendo la una como la otra un apoyo que permitió validar la información recabada en las entrevistas en profundidad a través del empleo de encuestas a la población de estudio.

En consecuencia, el diseño de investigación corres- ponde a una de carácter descriptivo el cual consiste en describir fenómenos, situaciones, contextos y sucesos; esto es, detallar cómo son y se manifiestan. Por lo cual, lo que se busca es especificar las características del suceso a investigar más no indicar como se relacionan estas. Este tipo de investigación permitió mostrar los ángulos o dimensiones de un fenómeno, contexto o situación en un momento dado y no necesariamente considerar hipótesis causales u otras. En ese sentido, se trató de dimensionar la percepción, uso, limitaciones, inconvenientes y reconocimiento por parte de los usuarios de la cuidad de Bogotá de negocios de economía colaborativa sin generar una relación de correlación entre las variables investigadas. Con el fin de entender los retos y las posibilidades que tiene está a partir del contexto y la situación actual que viven estos negocios.

\section{Procedimiento}

El proceso llevado a cabo para la realización de la presente investigación consistió en 11 etapas ( $\mathrm{Fi}$ gura 2 de la página siguiente) en las cuales se identificó el problema, se plantearon unos objetivos y posteriormente se prosiguió con la elaboración de instrumentos y trabajo en campo; para dar lugar al análisis cualitativo y cuantitativo, que produjeron unas conclusiones, con lo que se dio por terminado el proceso de investigación y se elaboró un informe final.

\section{Confidencialidad y consentimiento informado:}

Se solicitó la participación de los investigados teniendo en cuenta la Ley 1581 (Congreso, 2012), que tiene por objeto desarrollar el derecho constitucional que tienen todas las personas a conocer, actualizar y rectificar las informaciones que se hayan recogido sobre ellas en bases de datos o archivos, y los demás derechos, libertades y garantías constitucionales a que se refiere el artículo 15 de la Constitución Política; así como el derecho a la información consagrado en el artículo 20 de la misma. Por lo cual se procede a informar el tipo de investigación, el propósito de esta, el tratamiento a la información obtenida y se solicita permiso para 
Identificación del problema o caso de estudio

Planteamiento de objetivos de

investigación

Población objeto de estudio

Revisión literaria

Elaboración de instrumentos

Trabajo en campo

Análisis de instrumento cualitativo

Análisis de instrumento cualitativo con SSPS

Elaboración de informe

Conclusiones finales

Informe fina
Se evidencia desconocimiento del término economía colaborativa. Se observa poca legislación entorno a estos negocios. Se evidencia un aumento de estos negocios en la ciudad de Bogotá.

Se plantean los objetivos de la investigación los cuales están relacionados con el uso. Legislación, inconvenientes, limitantes, percepción. Conocimiento y canales de comunicación entorno a los negocios de economía colaborativa.

Se opta por una población residente en Bogotá, con edad entre 18 a 60 años y que ha usado este tipo de negocios.

Se buscan documentos que amplien la visión y generen un contexto sobre los negocios de la economía colaborativa en diferentes partes del mundo desde sus antecedentes hasta los problemas legales que presentan.

Se emplean dos instrumentos: encuestas y entrevistas en profundidad los cuales basan sus interrogantes en la consecución de los objetivos propuestos.

Se concuerdan las citas con los entrevistados de acuerdo a su disponibilidad de tiempo se procede a aplicar entrevista en profundidad. Se aplica técnica de bola de nieve para la realización de encuestas. El envió se realiza por medios electrónicos.

Se analiza mediante matriz las opiniones en conjunto primero de expertos y luego de consumidores.

Se procede a correr la base datos en software SSPS analizando pregunta por pregunta en función de los objetivos propuestos.

Se realiza un primer informe con toda la información obtenida hasta el momento y se procede a unificar la información.

Se procede a las conclusiones finales en base a la información obtenida, revisión literaria, método cualitativo y cuantitativo.

Se genera el informe final el cual corresponde al contenido obtenido durante todas las etapas anteriores.

Figura 2.

Procedimiento de la investigación.

Fuente: Elaboración propia (2020)

grabar y dar a conocer su nombre; con fin de cumplir con los propósitos de la investigación y dejar claro a los participantes el tratamiento que se le dará a sus datos e información obtenida. Además, cabe resaltar que para la aplicación de la encuesta no se solicita ningún dato personal más allá de los datos demográficos como son la edad, ocupación, estado civil y género, los cuales fueron dados a conocer únicamente en resúmenes numéricos que no permiten acceder a la identidad o datos personales de las personas participantes en la investigación. En el Anexo 3 y 4 se puede observar el guion de cada uno de los instrumentos aplicados para la investigación.

\section{Resultados}

A partir del método de investigación utilizado se presenta a continuación los resultados obtenidos; donde se evidencia el conocimiento que tienen los usuarios de este nuevo modelo económico, encontrándose que no tienen claridad acerca de lo que es la economía colaborativa (Figura 3); tan solo el $34,0 \%$ de la población encuestada indican conocer la misma a pesar de que hacen uso de esta. Ignorando por tanto los beneficios y bondades que les puede brindar al utilizar sus servicios, y el aporte que esta puede ofrecer a la sociedad como son la generación de nuevos tipos de trabajo, apoyo a las empresas pequeñas y al emprendimiento; mediante la reducción del impacto negativo al ambiente, y los beneficios propiamente al consumidor, como son la optimización de costos, conocer nuevas personas, la disponibilidad que ofrece de 24 horas al día, entre otros.

\section{"Se evita uno el desplazamiento por que los pro- ductos le llegan a la casa, no, que eso también es comodidad"}

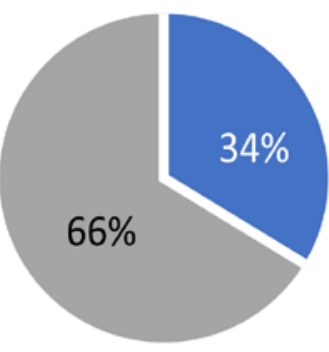

Conoce el término "Economía colaborativa"

No conoce el término "Economía colaborativa"

\section{Figura 3.}

Conocimiento del término economía colaborativa.

Fuente: Elaboración propia sobre la base de encuestas realizadas software SSPS.

Por otra parte, se refleja que los sectores más representativos de este tipo de negocios enfocados en la economía colaborativa son: el sector movilidad y domicilios. Siendo entonces Uber la plataforma más utilizada del sector movilidad, lo cual puede estar relacionado con que esta sea una de las aplicaciones pioneras de economía colaborativa en varias regiones del mundo, de allí que sea más factible que una mayor cantidad de usuarios la utilicen y la conozcan, posteriormente encontramos a Beat $26,2 \%$ y Picap con el $12,6 \%$, aplicaciones de igual manera representativas de este sector. Mientras, que en el sector de domicilios es Rappi la que lidera el uso por parte de los usuarios seguido de Domicilios.com con el 21,5\% y Uber Eats 2,7\%. 
En cuanto al sector de educación Duolingo 44,7\% y Wikipedia $13,3 \%$ son los más representativos. Entre tanto, en el sector de turismo Trivago y Despegar son las plataformas de mayor uso seguido de Booking 10,6\% y posteriormente Airbnb 4,4\%. Finalmente, en las plataformas financieras se evidencia un porcentaje muy bajo de utilización de estos aplicativos, ya que el $65,4 \%$ de la población indicó que no hacen uso de plataformas pertenecientes a este sector, siendo Daviplata la aplicación de mayor uso en el mismo, aunque cabe resaltar que esta no es propiamente una aplicación que opere bajo este modelo económico; además de la tendencia de los usuarios de confundir las aplicaciones bancarias con las aplicaciones de economía colaborativa pertenecientes al sector financiero, pues, aunque son de finanzas no necesariamente pertenecen a este tipo de economía.

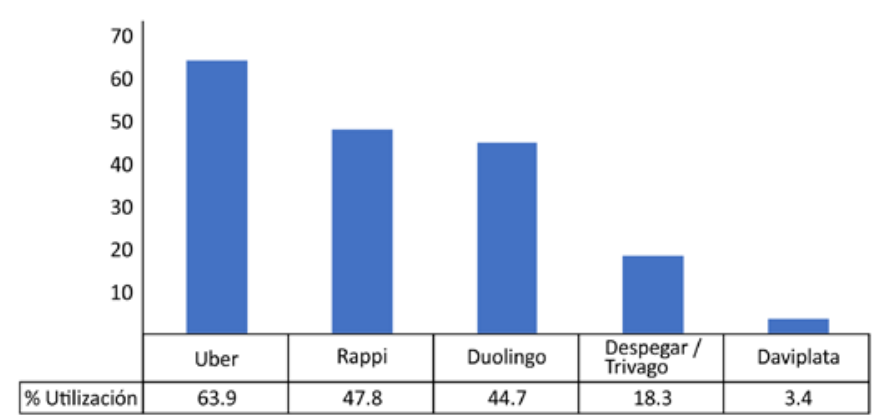

Figura 4.

Plataforma de mayor uso de acuerdo con cada sector.

Fuente: Elaboración propia sobre la base de encuestas realizadas software SSPS.

Respecto a la percepción que tienen los usuarios de los negocios pertenecientes a la economía colaborativa, se encontró que en su mayoría es positiva, siendo calificativos como la optimización de tiempo, eficaz, amigable y que satisfacen necesidades, la descripción que dan los usuarios hacia este tipo de negocios (Figura 5). Además, estos han facilitado y aportado una manera cómoda de realizar las cosas, gracias a la inmediatez y a la falta de tiempo del consumidor, debido a su uso desde casa o lugar de trabajo, evitando desplazamientos. Sin embargo, los calificativos como el costo y la seguridad son aspectos que tienen una percepción más baja en los usuarios; siendo por tanto aspectos por mejorar, como también lo son: la ciberdelincuencia, sobreoferta y la saturación en el mercado de servicios.
"La inseguridad de la ciberdelincuencia, creo que hay personas que pueden aprovecharse entonces para mi eso es una restricción importante"

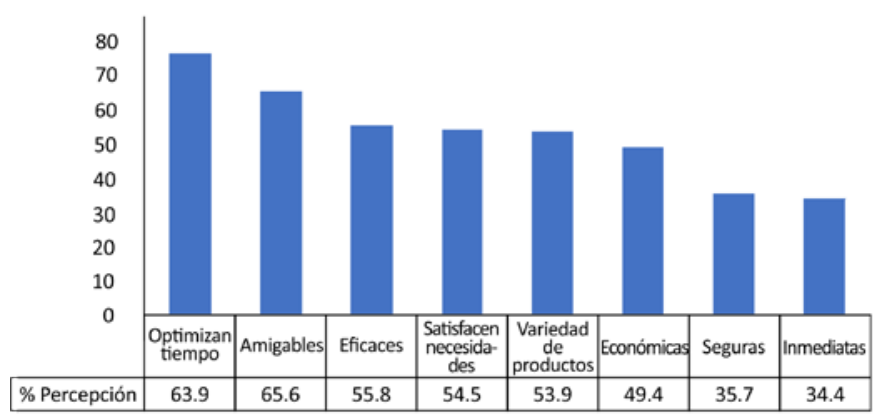

Figura 5.

Percepción de los consumidores sobre economía colaborativa.

Fuente: Elaboración propia sobre la base de encuestas realizadas software SSPS.

Asimismo, se evaluó cuáles son los canales de comunicación por los cuales los usuarios de estos negocios enfocados en economía colaborativa obtienen información de estos, siendo las redes sociales, navegando en Internet y voz a voz los principales canales (Figura 6 de la página siguiente). No obstante, aún es necesario mejorar aspectos como el incremento en la divulgación, publicidad y ajustar lo relacionado con social media en cuanto al contenido de opiniones y recomendaciones, ya que es fundamental para los usuarios en el momento de decidirse a utilizar estos negocios. Además de abrir bases de datos donde el consumidor sea quien pueda elegir al personal. Igualmente, los usuarios esperan que los negocios de economía colaborativa a través del tiempo se posicionen y les proporcionen muchas más facilidades, donde continúen mejorando con la asequibilidad, facilidad y comodidad de procesos de compra.

Respecto a los limitantes con los que se han encontrado los usuarios para poder utilizar las plataformas de economía colaborativa, los más frecuentes son: la cobertura, demora, acceso a Internet y la publicidad que muestran las mismas. Sin embargo, cabe mencionar que el $26,7 \%$ de los usuarios no han tenido inconvenientes para hacer uso de estos negocios (Figura 7) de acuerdo con ello se puede concluir que los consumidores se han enfrentado a varios condicionamientos que les im- 


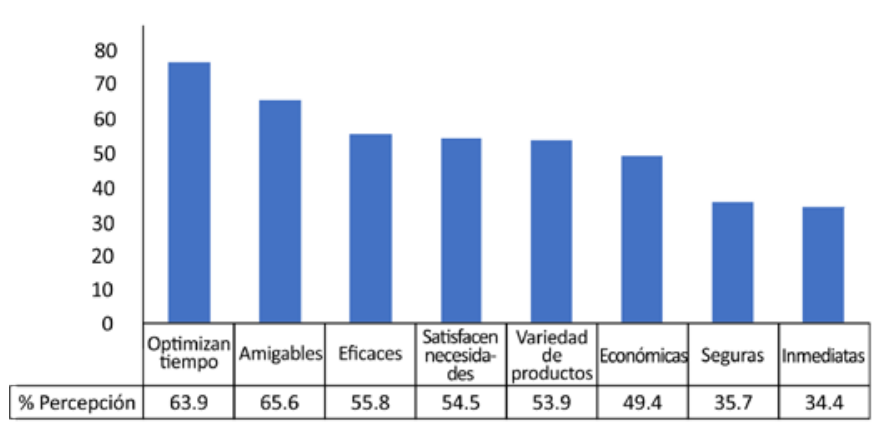

Figura 6.

Canales de comunicación para informarse sobre economía colaborativa

Fuente: Elaboración propia sobre la base de encuestas realizadas software SSPS.

pide hacer un uso óptimo, lo que es un llamado a este tipo de negocios para que verifiquen y eviten estas limitaciones a los usuarios; igualmente, para que constantemente se reinventen y verifiquen todas las falencias posibles, aprovechando los comentarios que hacen los usuarios en sus aplicativos y así la satisfacción se incremente, para evitar que la población que aún no ha experimentado ninguna limitación, tengan que enfrentarse a estas.

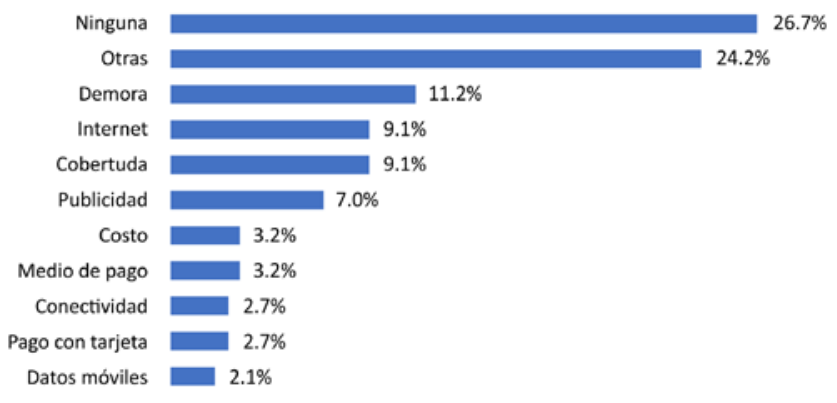

Figura 7.

Limitaciones para poder acceder a negocios de economía colaborativa.

Fuente: Elaboración propia sobre la base de encuestas realizadas software SSPS.

De igual manera, los principales inconvenientes que se han presentado al utilizar las plataformas móviles son los expuestos en la Figura 8, donde la pérdida de tiempo es uno de los factores más representativos con los que se han encontrado los usuarios al hacer uso, aspecto que ha de mejorarse, pues a pesar que estos negocios ofrecen la posibilidad de optimizar tiempo evitando desplazamientos, el $32,4 \%$ de la población encuestada considera que en algún momento les han generado una pérdida del mismo. De igual manera el robo y las discusiones con el prestador de servicio, son factores que influyen de manera negativa sobre el usuario y deja ver la importancia de que exista un componente de legalidad que facilite el seguimiento continuo y oportuno. Así como también se propicien espacios de capacitación que permitan mejorar y brindar un servicio de calidad para poder hacer frente a las diferentes situaciones laborales que se puedan presentar, lo anterior se verá reflejado en la seguridad y satisfacción del usuario.

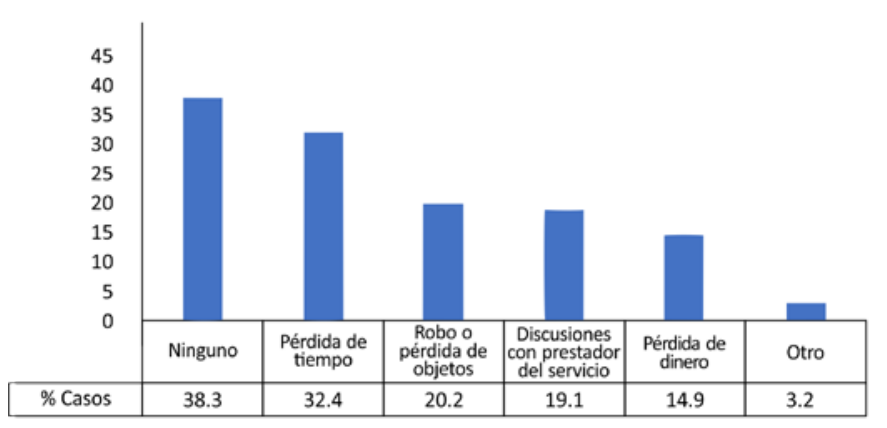

\section{Figura 8.}

Inconvenientes para poder acceder a negocios de economía colaborativa.

Fuente: Elaboración propia sobre la base de encuestas realizadas software SSPS.

Por otro lado, en consideración a la influencia de las TIC en la economía colaborativa, se encontró que está es fundamental, ya que permite su funcionamiento; al ser el medio por el cual los usuarios pueden acceder, al facilitar y agilizar los procesos y reducir los tiempos de espera. Sin embargo, aún quedan retos por afrontar en torno a este tema, como la cobertura y el acceso a dispositivos tecnológicos. También, hace falta mejorar el tema cultural, pues no todos los usuarios se encuentran listos para proporcionar información personal, interactuar o confiar en estas. Siendo entonces un impedimento para el usuario el analfabetismo tecnológico, el acceso a internet, la cobertura, la intangibilidad, el cuidado de datos personales, el uso de tarjeta de crédito en ciertos casos, el miedo y las malas experiencias. Entre tanto, la desconfianza, la inseguridad y el desconocimiento son uno de los principales motivos por los cuales los usuarios aún no se encuentran convencidos de comenzar a utilizar este tipo de negocios, lo que se vuelve un reto para la misma. 
"La economía colaborativa se basa en tecnología y el papel como te digo es transcendental completamente porque es la forma cómo generamos ese puente"

"El acceso que aún es restringido sobre todo para el área rural"

En cuanto a lo que concierne a la legislación en Colombia, como se evidencia en el marco teórico existen contradicciones y legislación ambigua, que deja entrever que las leyes y regulaciones que hasta el momento se tienen no ofrecen claridad para las relaciones comerciales que tienen estos negocios; a pesar de que no hay normativa concreta esto no es un factor que afecte de manera significativa al consumidor para la utilización de estos servicios. Para ellos es más importante conocer las experiencias que han vivido, restándole importancia al tema legal y si este factor llegara a afectar, la preocupación está orientada a la posibilidad de que se puedan llegar a clausurar estas plataformas; ya que no podrían utilizarlas ni obtener sus beneficios.

Además, el conocimiento por parte del público en este aspecto es ambiguo. A pesar de ello, es conveniente que el gobierno promueva la legalidad, pues de esta manera se genera un impulso, que permitiría que el usuario esté más protegido respecto a sus datos personales y las garantías sobre el servicio que reciben, y permitir de alguna manera un servicio de mayor confiabilidad, que disminuya las barreras producidas por estos vacíos jurídicos que pueden afectar al consumidor $y$ al proveedor acerca de la competencia desleal, impuestos e inclusive la vinculación laboral y las garantías que aplicaciones como Uber ofrece a sus trabajadores; es así que, la ausencia de normatividad es uno de los grandes obstáculos de la economía colaborativa.

"Uno como usuario no se pone uno a buscar de eso a mi desde que me brinden el servicio y ya"

Finalmente, cabe mencionar que la población más receptiva a esta clase de negocios ha sido la de adultos jóvenes como estudiantes y empleados; lo que puede estar directamente ligado a la alfabetización tecnológica y los recursos económicos que se necesitan en algunos casos para disponer de las mismas. Así como, también el contexto social en el que se mueven estos individuos pues por sus obligaciones, requieren de optimización de tiempo y espacio. Siendo entonces las amas de casa la población que menos recurre al uso de estos negocios, situación que puede estar relacionada con sus actividades diarias y con la posibilidad de acceder a estos.

\section{Discusión y Conclusiones}

En conclusión, la economía colaborativa es una realidad en la ciudad de Bogotá, pese a las dificultades que afronta a diario y al desconocimiento por parte del usuario con el término economía colaborativa que no implica un menor uso; pero que sí genera que se desaprovechen y se desconozcan ciertos beneficios que otorga este modelo de negocio.

Además, se evidenció que la economía colaborativa ha sido acogida de manera positiva entre los usuarios, tanto en Colombia como en muchas regiones del mundo; convirtiéndose en una nueva alternativa que posibilita el uso de recursos de manera efectiva. Siendo aspectos como la efectividad, la optimización de tiempo, el ser amigables, el ofrecer variedad de productos y satisfacer necesidades, los calificativos que en su mayoría utilizan los usuarios al referirse a estos negocios. Lo que podría significar un incremento de confianza en los usuarios hacia el mercado de la economía colaborativa. Siendo la misma un factor clave; pues, el consumo colaborativo se construye a partir de mecanismos en línea, como son los comentarios, las puntuaciones y las opiniones, información determinante a la hora de decidirse a usar estos negocios. Lo anterior podría significar que se están modificando los hábitos de consumo de los individuos.

No obstante, todavía se presenta inseguridad por parte de los usuarios al momento de brindar sus datos personales y/o bancarios, inseguridad por posibles situaciones de robo, pérdida de tiempo o discusiones con el prestador del servicio y algunas discrepancias en relación con el costo, aunque la mayoría de estos negocios ofrecen precios asequibles y menores en comparación a sectores tradicionales, para algunos usuarios aún estas tarifas son altas. Esto significa que, aunque la percepción es positiva, aún se tienen algunos aspectos por supe- 
rar y en lo que se deberá trabajar para mejorar la experiencia de los usuarios.

Por otra parte, fue posible reconocer que la economía colaborativa tiene un gran reto por afrontar en relación a las TIC pues estos negocios, cuya herramienta principal es la tecnología e Internet, a pesar de que se supone que estamos viviendo los nuevos y últimos avances de la era tecnológica, que cada vez revolucionan más la manera en como los seres humanos se relacionan e interactúan con los demás y que asimismo, ha facilitado infinidad de tareas cotidianas; aún presenta deficiencias ya que no todas las personas pueden surtir los beneficios y avances de la tecnología, incluso algunas personas no han interactuado ni una sola vez con la misma.

En Colombia, a pesar de que el gobierno colombiano está brindando zonas wifi gratis y con ello están permitiendo acceso más factible; según Iván Mantilla, el viceministro de conectividad y digitalización, actualmente alrededor de unos veinte millones de personas no cuentan aún con acceso a Internet, especialmente las poblaciones de zonas rurales carecen de este servicio (Redacción, 2019). Convirtiéndose en un desafío, como fue expresado por los usuarios, este es uno de los limitantes e inconvenientes más frecuentes para hacer uso de estos negocios, por lo que la demanda se ve afectada ya que, al ser el principal medio de acceso a la misma, limita su funcionamiento y por ende la posibilidad de expandirse. Por lo que los negocios bajo este enfoque deberán enfrentarse a este desafío para poder ofrecerle a todas las personas un servicio de calidad y aumentar la cobertura; para esto, se podrían apoyar en el Ministerio de las Tecnologías de la Información y las Comunicaciones MinTIC al igual que en proyectos como Connecting The Dots o el Caribe Biz Fórum donde se promueve y se impulsan este tipo de negocios enfocados en la economía colaborativa.

Así mismo se deberá resolver el tema legislativo, ya que no existe normativa puntual, ni clara para promover el óptimo funcionamiento de estos negocios ya que, por el contrario, su falta ha facilitado choques entre sectores aduciendo a competencia desleal. Aunque como se mencionó en realidad para el consumidor la ilegalidad no es determinante para su uso, si es un tema que le impide desarro- llarse con las garantías y normativa que permita un funcionamiento y competitividad en condiciones de igualdad y ofrezca la seguridad que como usuarios requieren para mayor tranquilidad y eficiencia en la relación con este tipo de negocios.

Finalmente, cabe constatar que la social media (las redes sociales como Facebook e Instagram) a través de la tecnología móvil y voz a voz han sido esenciales para la expansión de este modelo económico, por lo que seguir utilizando estos medios y aprovechar su potencial puede ser determinante para seguir creciendo. Además, los sectores más relevantes en cuanto a uso son movilidad, domicilios y educación con plataformas como Uber, Beat, Rappi, Domicilios.com, Duolingo y Wikipedia. Siendo el sector de finanzas y turismo los que cuentan con menos usuarios o de los que menos se tiene conocimiento.

\section{Agradecimiento}

La presente investigación hace parte de un proceso académico llevado a cabo por parte de los investigadores, razón por la cual esta no contó con el financiamiento, ni apoyo económico de ninguna organización o particular para su realización.

\section{REFERENCIAS BIBLIOGRÁFICAS}

Alfonso, R. (2016). Economía colaborativa: un nuevo mercado para la economía social. España: CIRIEC-Espańa, revista de economía pública, social y cooperativa.

Algar, R. (2007). Collaborative Consumption. Leisure Report.

Amaya, M. P., \& Forero Carrillo, H. D. (2016). Intervención estatal en la economía colaborativa: Crowdfunding en Colombia. Bogotá D.C.

Barragán, J., Guerra, P., Villalpando, P., Segura, I. A., \& Sandoval, P. (2017). Modelos de negocios basados en el concepto de economía colaborativa: análisis de factores característicos y casos ilustrativos. México: Daena: International Journal of Good Conscience.

Batista-Domínguez., M. R. (2018). Nuevas formas de empleo en la era de Economías Colaborativas. New forms of employment in the era of Collaborative Economies. Innovación Tecnológica.

Beltrán, A. (2018). Plataformas de Economía Colaborativa: 
Una mirada global. Espańa: The Ostela School Of Tourism \& Hospitality.

Buenadicha, C., Cañigueral, A., \& De León, I. L. (2017). Retos y posibilidades de la economía colaborativa en América Latina y el Caribe. Banco Interamericano de Desarrollo. https://doi.org/10.18235/0000707

Cámara Colombiana de Comercio Electrónico. (2019, 30 de septiembre). Avanza iniciativa para regular la Economía Colaborativa Digital. Bogotá, Bogotá, Colombia. Recuperado de https://www.ccce.org.co/noticias/avanza-iniciativa-para-regular-la-economia-colaborativa-digital/

Congreso. (2012). Ley 1581 del 17 de octubre de 2012: por la cual se dictan disposiciones generales para la protección de datos personales. Congreso de Colombia.

DANE. (2019, 3 de mayo). Pobreza monetaria. Bogotá.

Durán, A., Álvarez, J., del Río Rama, M. d., \& Maldonado, C. P. (2016). Economía Colaborativa: Análisis de la producción científica en revistas académicas. São Paulo: Revista de Gestão e Secretariado -GeSec.

Europea, C. (2016). Una Agenda Europea para la economía colaborativa. Bruselas: COM.

Ferrari, A. P. (2018, 14 de septiembre). Teoría de percepción del consumidor. Recuperado de Cuida tu dinero:

https://www.cuidatudinero.com/13174248/teoria-de-percepcion-del-consumidor

Gómez, M. V., \& Pérez, N. (2018). Desafíos de los emprendimientos de economía colaborativa en Colombia. Medellín: Revista Loginn.

Hernández S., R., Fernández C., C., \& Baptista L., P. (2014). Metodología de la investigación. McGraw-Hill.

Hernández, R., Fernández, C. \& Baptista, M. (2014). Metodología de la Investigación (5a ed.). México: Mc. Graw-Hill.

Máynez, G., \& Gutiérrez, M. (2016). Matchmaking: el surgimiento de la economía colaborativa. Madrid: Llorente \& Cuenca.

Medrano, M. L., \& Aza, M. (2018). Economía Colaborativa, oportunidades disruptivas. Espańa: Revista de estudios de juventud.

Ordońez- de- Haro, J., \& Torres, J. (2019). Economía colaborativa y regulación: un análisis prospectivo. España: CICE. https://doi.org/10.32796/cice.2019.97.6798

Quintero, M. I. (2018). Economías colaborativas, nuevas tendencias de consumo y retos para Latinoamérica y Colombia. Bogotá: Revista Campos en Ciencias Sociales.

Rabasco, N. P. (2016). Análisis de la incidencia de la economía colaborativa en el turismo en Mallorca: el paradigma “Airbnb”. Departament d'Economia Aplicada.

Redacción. (2019, 17 de mayo). 20 millones de personas en Colombia no tienen conexión a internet: Viceministro de Conectividad. Diario La Libertad.

Rodríguez, R., Pérez, M. d., \& Svensson, G. (2017). Mode- los de negocio en la economía colaborativa: síntesis y sugerencias. ESIC Business \& Marketing School.

Sarasola, K. (2016). La Economía Colaborativa hay que regularla, pero con inteligencia. Banco Interamericano de Desarrollo.

Sobrino, M., \& Maudes, A. (2016). La regulación debe justificarse por la existencia de fallos de mercado como la información asimétrica o la existencia de externalidades. Banco Interamericano de Desarrollo.

Taylor, S., \& Bogdan, R. (2000). Introducción a los métodos cualitativos. Espańa: Paidos.

Walters, R. (2017). Realizing the Potential of the Sharing Economy in Asia. Washington, D.C.: The Heritage Foundation. 
Adriana Salazar Yaquino, Ivonne Pedraza Gonzalez y Maria Lombana Gonzalez

\section{Anexos}

\section{Anexo I:}

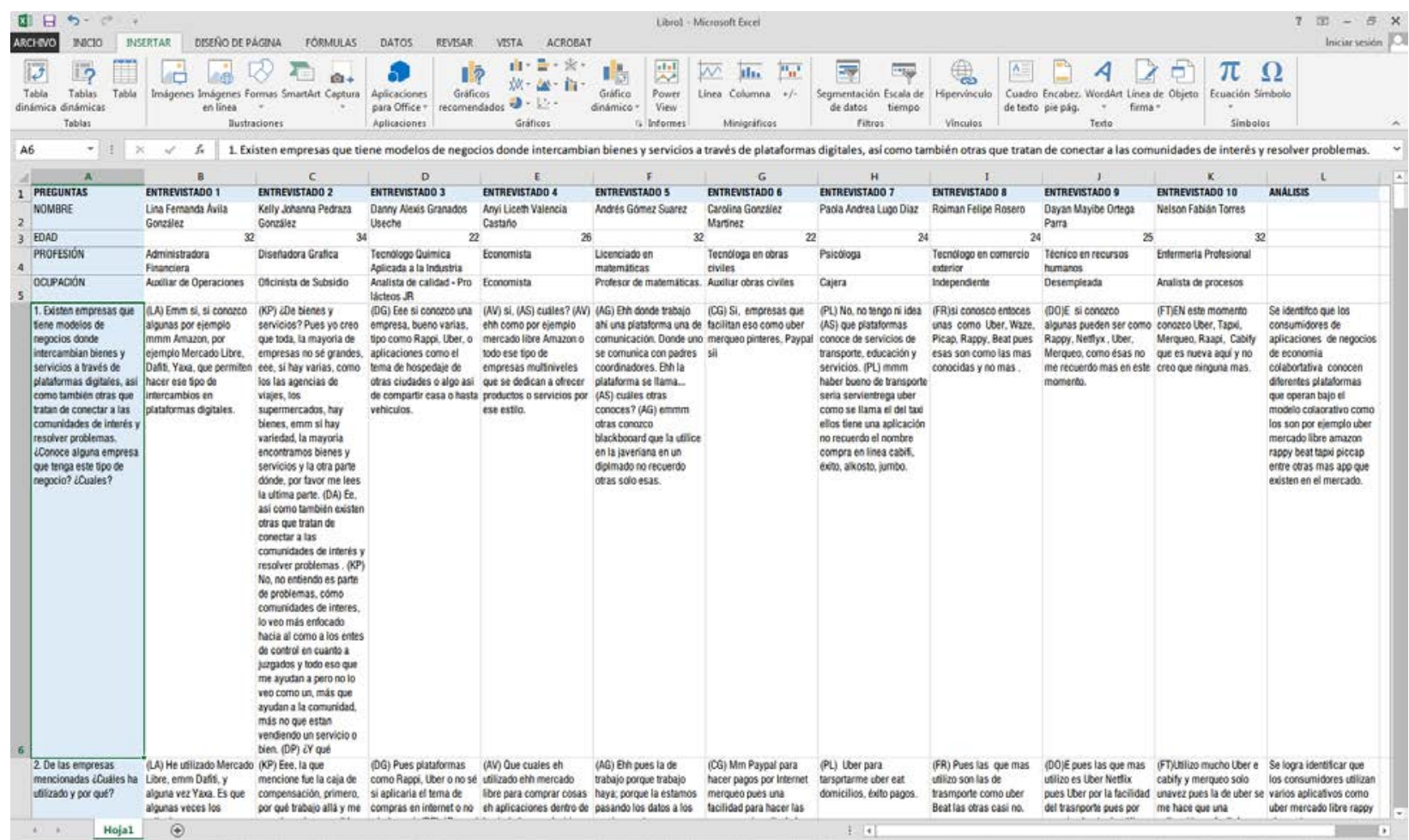

\section{Anexo 2:}

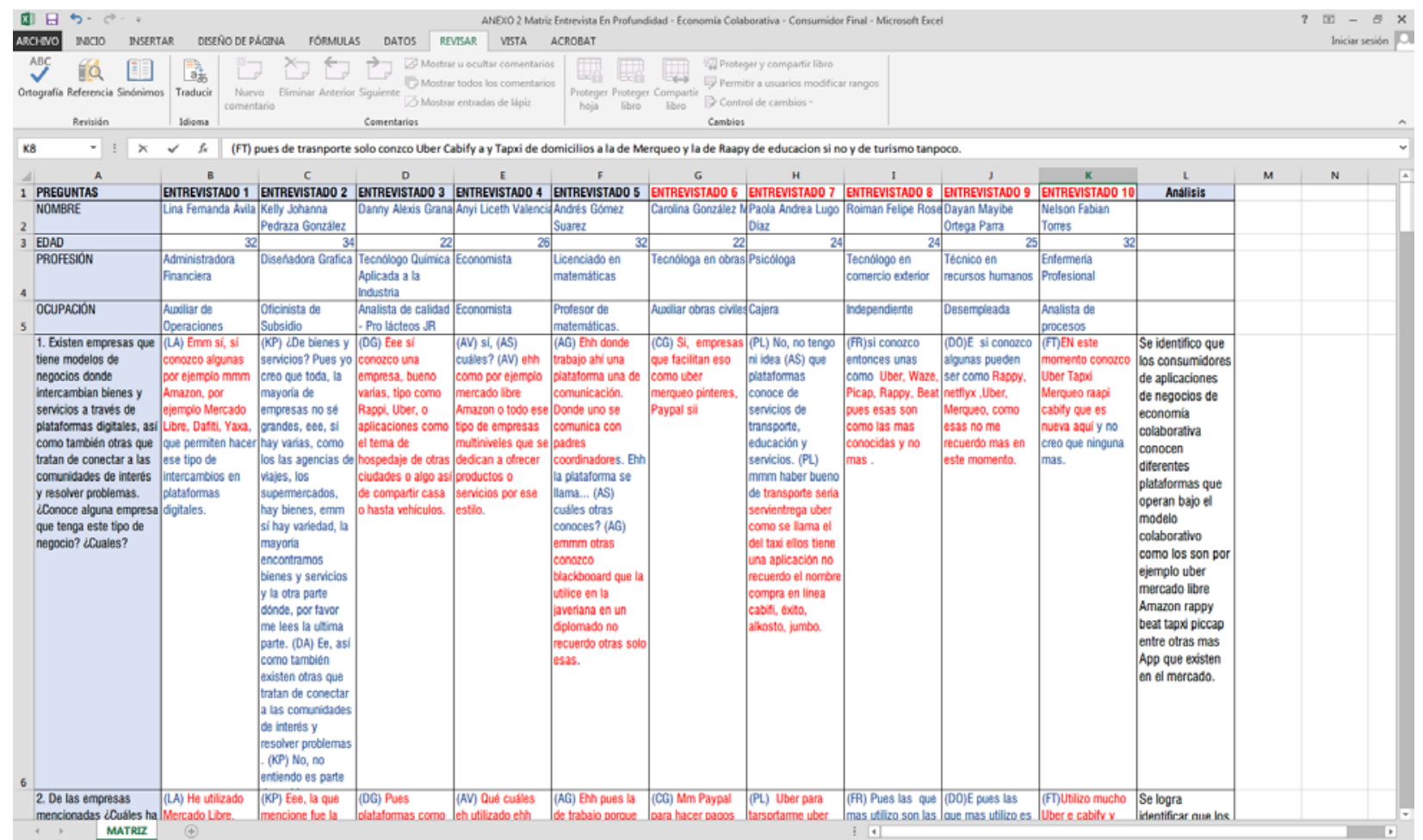


Anexo 3: Instrumentos CUALitativos.

\section{Entrevistas en profundidad experto.}

Saludo y presentación:

Buen día, mi nombre es (x) soy estudiante de investigación de mercados del Sena; en la actualidad me encuentro desarrollando una investigación a cerca de los retos y posibilidad con los que cuentan los negocios de economía colaborativa en la ciudad de Bogotá. Quiero agradecerle su tiempo y el haber aceptado la invitación a hacer parte de este procedimiento donde su opinión será de gran utilidad para los propósitos de esta investigación.

Lo que haremos en esta ocasión es una entrevista en profundidad individual para conocer la opinión que usted tiene del tema de manera abierta.

La información será confidencial y únicamente se utilizará con fines de análisis cualitativo en donde se tendrán en cuenta de forma conjunta la información recolectada de todos los entrevistados, por lo tanto, no se hará énfasis en los datos mencionados por alguien en particular.

Teniendo en cuenta la importancia de sus opiniones, la entrevista será grabada únicamente en audio, para que sus aportes no se pierdan por dejarlos en mi memoria, nuestro compromiso es guardar la confidencialidad de sus opiniones.

En este orden de ideas ¿Usted está de acuerdo con lo anteriormente mencionado y que su nombre y el de la institución sean referenciados en esta investigación?, en caso contrario podemos manejarlo de manera confidencial.

El manejo de datos personales será bajo lo estipulado en la ley 1581 de 2012, donde se dispone los parámetros bajo los cuales deben ser tratados sus datos personales. Asimismo, tiene derecho a conocer, actualizar y rectificar los datos personales proporcionados, a solicitar prueba de esta autorización y a solicitar información sobre el uso que se les ha dado a sus datos personales.

\section{Tiempo: 2 minutos}

1. Identificar cual es conocimiento que tienen los bogotanos con referencia a los negocios de economía colaborativa.

- Desde su punto de vista ¿Que conocimiento cree que tiene el consumidor colombiano a cerca de economía colaborativa?

- De la experiencia que usted ha tenido ¿Cuáles son los negocios de economía colaborativa que más han impactado? ¿Por qué?

\section{Tiempo: 3 minutos}

2. Conocer la percepción y grado de confianza por parte del consumidor bogotano hacia los negocios de economía colaborativa.

- ¿Qué opina usted de los negocios de economía colaborativa?

- Para usted ¿Cuál es el aporte que ha traído este nuevo modelo de economía colaborativa al país?

- Según su percepción ¿Cuáles son los aspectos positivos de los negocios o plataformas de economía colaborativa?

- Según su percepción ¿Cuáles son los aspectos negativos de los negocios o plataformas de economía colaborativa?

- ¿Con base a su experiencia que aspectos considera que debería tener una plataforma de economía colaborativa para ser más confiable?

\section{Tiempo: 10 minutos}

3. Evidenciar cual es la frecuencia y lugar de consumo de los bogotanos hacia los productos y servicios ofrecidos por los negocios de economía colaborativa.

- ¿Qué plataformas de economía colaborativa conoce?

- ¿Cuáles cree que son las plataformas economía colaborativa de mayor uso por parte del consumidor colombiano?

- De qué manera cree usted que está influenciando la economía colaborativa en los hábitos de consumo y compra en el consumidor colombiano.

\section{Tiempo: 5 minutos}

4. Registrar cuales son los canales de comunicación por los que actualmente los bogotanos 
adquieren información sobre los negocios de economía colaborativa.

- Según su experiencia ¿Cuáles son los canales de comunicación más frecuentes para dar a conocer las plataformas de economía colaborativa?

\section{Tiempo: 2 minutos}

5. Establecer que tanto influye la legislación y normatividad en el consumidor al momento de adquirir un producto o servicio proveniente de negocios de economía colaborativa.

- ¿Que conoce usted acerca de la regulación de las plataformas de economía colaborativa? De acuerdo a la respuesta: ¿porque cree que está pasando esto? ¿En qué consiste? Continuar con la otra pregunta.

- Como parte de la investigación que estamos desarrollando no hemos encontrado nada concreto con respecto a la legislación que rige este tipo de plataformas de economía colaborativa (mencionar caso Airbnb y Uber). ¿Usted porque cree que está pasando esto?

- ¿Cómo cree usted que influye esta carencia en el consumidor al momento de adquirir un producto o servicio de negocios de economía colaborativa?

\section{Tiempo: 10 minutos}

6. Evaluar las inconformidades y expectativas de los consumidores bogotanos con respecto a los negocios de economía colaborativa.

- ¿Cuáles serían lo limitantes a los que se enfrenta el consumidor colombiano al momento de adquirir un producto o servicio por medio de alguna de plataformas de economía colaborativa?

- ¿Qué considera que deberían mejorar las plataformas de economía colaborativa para ser más exitosas?

\section{Tiempo: 5 minutos}

7. Reconocer cual es la influencia de las tecnologías de la información y las comunicaciones en los negocios de economía colaborativa.

- ¿Cuál es el papel de las TIC en el desarrollo de las plataformas de economía colaborati- va?

- ¿A qué retos cree usted que se enfrenta la economía colaborativa en relación con las TIC?

- ¿Qué tanto considera que ha avanzado Colombia en temas de tecnología en relación con economía colaborativa?

- Quisiera agregar algo más sobre este tema. Gracias por su tiempo.

\section{Entrevista en profundidad consumidor}

Saludo y presentación: Buen día, mi nombre es (x) soy estudiante de investigación de mercados del Sena; en la actualidad me encuentro desarrollando una investigación a cerca de los retos y posibilidades con los que cuentan los negocios donde se intercambian bienes y servicios a través de plataformas digitales, así como también otras que tratan de conectar a las comunidades de interés y resolver problemas en Bogotá. Quiero agradecerle su tiempo y el haber aceptado la invitación a hacer parte de este procedimiento donde su opinión será de gran utilidad para los propósitos de esta investigación.

Lo que haremos en esta ocasión es una entrevista en profundidad individual para conocer la opinión que usted tiene del tema de manera abierta.

La información será confidencial y únicamente se utilizará con fines de análisis cualitativo en donde se tendrán en cuenta de forma conjunta la información recolectada de todos los entrevistados, por lo tanto, no se hará énfasis en los datos mencionados por alguien en particular.

Teniendo en cuenta la importancia de sus opiniones, la entrevista será grabada únicamente en audio, para que sus aportes no se pierdan por dejarlos en mi memoria, nuestro compromiso es guardar la confidencialidad de sus opiniones.

En este orden de ideas ¿Usted está de acuerdo con lo anteriormente mencionado y que su nombre sea referenciado en esta investigación?, en caso contrario podemos manejarlo de manera confidencial.

El manejo de datos personales será bajo lo estipulado en la ley 1581 de 2012, donde se dispone los parámetros bajo los cuales deben ser tratados sus 
datos personales. Asimismo, tiene derecho a conocer, actualizar y rectificar los datos personales proporcionados, a solicitar prueba de esta autorización y a solicitar información sobre el uso que se le ha dado a sus datos personales.

\section{Tiempo: 2 minutos}

1. Conocer la percepción y grado de confianza por parte del consumidor bogotano hacia los negocios de economía colaborativa.

- Existen empresas que tiene modelos de negocios donde intercambian bienes y servicios a través de plataformas digitales, así como también otras que tratan de conectar a las comunidades de interés y resolver problemas. ¿Conoce alguna empresa que tenga este tipo de negocio? ¿Cuáles?

- De las empresas mencionadas ¿Cuáles ha utilizado y por qué? (Sí la persona responde que no, realizar esta pregunta ¿Qué plataformas conoce de servicio de transporte, domicilios, educación, fianzas, turismo y alojamiento? Nómbrelas, por favor.)

- ¿Qué plataformas conoce de servicio de transporte, domicilios, educación, fianzas, turismo y alojamiento? Nómbrelas, por favor.)

- (Sí definitivamente la persona desconoce el tema y no asocia a algo similar, nombrar ejemplos como: Uber, Rappi u otros, sin nombrar el termino economía colaborativa)

- ¿Qué plataformas conoce de servicio de transporte, domicilios, educación, fianzas, turismo y alojamiento?

- ¿Qué opina usted de estos tipos de negocios?

- ¿Cuáles son las ventajas de este tipo de negocios?

- ¿Cuáles son las desventajas de este tipo de negocios?

\section{Tiempo: 10 minutos}

2. Evidenciar cual es la frecuencia y lugar de consumo de los bogotanos hacia los productos y servicios ofrecidos por los negocios de economía colaborativa.

Teniendo en cuenta las empresas que usted menciono, cuéntenos:
- ¿En qué momentos o situaciones utiliza usted este tipo de negocio?

- ¿Cada cuanto hace uso de estos tipos de negocios?

- ¿Cuáles son los motivos por los cuales utiliza este tipo de negocios?

\section{Tiempo: 5 minutos}

3. Registrar cuales son los canales de comunicación por los que actualmente los bogotanos adquieren información sobre los negocios de economía colaborativa.

- ¿Cómo conoció por primera vez estos modelos de negocio?

- Actualmente ¿De dónde obtiene información de las modificaciones, promociones, productos o servicios de las aplicaciones móviles que usted utiliza?

\section{Tiempo: 2 minutos}

4. Establecer que tanto influye la legislación y normatividad en el consumidor al momento de adquirir un producto o servicio proveniente de negocios de economía colaborativa.

- ¿Qué conoce de la legalidad de este modelo de negocios?

- ¿En qué aspecto le afecta el tema de legalidad para la utilización de este tipo de negocios?

\section{Tiempo: 10 minutos}

5. Evaluar las inconformidades y expectativas de los consumidores bogotanos con respecto a los negocios de economía colaborativa.

- ¿Alguna vez ha tenido algún inconveniente con este tipo de negocios? Cuéntenos con cual y que inconveniente.

- ¿Qué tipo de limitaciones ha encontrado con respecto al uso de este tipo de negocios?

- ¿Qué expectativas tiene sobre este tipo de negocios, para su estilo de vida?

\section{Tiempo: 5 minutos}

6. Reconocer cual es la influencia de las tecnologías de la información y las comunicaciones en los negocios de economía colaborativa.

- ¿Cuál considera usted que es el papel de la tecnología en este tipo de negocios? 


\section{Tiempo: 7 minutos}

7. Identificar cual es conocimiento que tienen los bogotanos con referencia a los negocios de economía colaborativa.

- ¿Ha escuchado usted alguna vez sobre el termino económica colaborativa? ¿Qué ha oído hablar?

- ¿Conoce usted algún negocio que funcione mediante el modelo colaborativo de aplicativos móviles o de plataformas tecnológicas?

\section{AneXo 4: InSTRUMENTo CUANTITATIVo.}

\section{Encuesta retos y posibilidades de la economía co- laborativa en Bogotá}

Buenos días, somos estudiantes de investigación de mercados del Centro de Gestión de Mercados, Logística y Tecnologías de la Información del Sena. Nuestros nombres son Adriana Salazar y Daniela Pedraza, actualmente nos encontramos desarrollando una investigación con el fin de determinar los retos y posibilidades de la economía colaborativa en Bogotá. Agradeceríamos que nos dedicara alrededor de quince minutos de su tiempo para contestarla estamos seguros de que sus respuestas ayudaran a cumplir con los propósitos de la investigación.

La información será confidencial y únicamente se utilizará con fines de análisis cuantitativos en donde se tendrán en cuenta de forma conjunta la información recolectada de todos los entrevistados, por lo tanto, no se hará énfasis en los datos mencionados por alguien en particular.

El manejo de datos personales será bajo lo estipulado en la ley 1581 de 2012, donde se dispone los parámetros bajo los cuales deben ser tratados sus datos personales. Asimismo, tiene derecho a conocer, actualizar y rectificar los datos personales proporcionados, a solicitar prueba de esta autorización y a solicitar información sobre el uso que se les ha dado a sus datos personales.

Si usted está de acuerdo y acepta lo anteriormente mencionado lo invitamos a continuar con la encuesta.

\section{Pregunta filtro}

¿Reside usted en la ciudad de Bogotá?

- Sí

- No

¿Ha adquirido productos o servicios por medio de una plataforma o aplicativo móvil?

- Sí

- No

¿Por qué motivo no ha adquirido productos ni servicios por medio de una plataforma o aplicativo móvil?

1. ¿Conoce el término economía colaborativa?

- Sí

- No

2. ¿Cuál es la plataforma o aplicativo móvil que utiliza usted del sector transporte?

3. ¿Cuál es la plataforma o aplicativo móvil que utiliza usted de domicilios?

4. ¿Cuál es la plataforma o aplicativo móvil que utiliza usted de educación?

5. ¿Cuál es la plataforma o aplicativo móvil que más utiliza usted del sector turismo?

6. ¿Cuál es la plataforma o aplicativo móvil que utiliza usted de finanzas?

7. ¿Cuáles son las plataformas o aplicativos móviles del sector transporte que usted conoce? Seleccione máximo dos opciones.

- Uber.

- Beat.

- Picap.

- InDriver.

- Cabify.

- DiDi.

- Ninguna

- Otra

8. ¿Cuáles son las plataformas o aplicativos móviles del sector turismo que usted conoce? Seleccione máximo dos opciones.

- Trivago.

- Airbnb. 
- Despegar.

- Via Colombia.

- PlanesTuristicos.com

- IntercambioCasas.

- Ninguna.

- Otras

9. ¿Cuáles son las plataformas o aplicativos móviles del sector domicilios que usted conoce? Seleccione máximo dos opciones.

- Rappi.

- Uber Eats.

- Domicilios.com.

- Mensajeros Urbanos.

- Vuelta App.

- Ninguna.

- Otra

10. ¿Cuáles son las plataformas o aplicativos móviles del sector educación que usted conoce? Seleccione máximo dos opciones.

- Duolingo.

- Bit.

- Language Amigo.

- Khan Academy.

- Geogebra.

- Wikipedia.

- Ninguna.

- Otra

11. ¿Cuáles son las plataformas o aplicativos móviles de ocio que conoce? Seleccione máximo dos opciones.

- Spotify.

- Netflix.

- YouTube.

- NerdBooks

- Ninguna.

- Otra

12. ¿Cuáles son las plataformas o aplicativos móviles del sector financiero que usted conoce? Seleccione máximo dos opciones.

- Ideame.

- Bhive.

- Arboribus.
- Comunitae.

- Ninguna.

- Otra

13. Ubique su calificación en la escala con el adjetivo que más se ajuste a su percepción. Donde 1 cumpliría con la condición de la izquierda y 4 cumpliría la condición de la derecha. Según su opinión las plataformas tecnológicas o aplicativos móviles son:

14. Las plataformas tecnológicas o aplicativos móviles:

15. ¿Con que frecuencia hace uso de las plataformas tecnológicas o aplicativos móviles? Seleccione una por sector.

16. Ordene según su criterio cuales considera que son las edades de las personas que están más abiertas al uso de plataformas tecnológicas o aplicativos móviles. Ordene de mayor a menor donde uno es la población que menos la utiliza y cuatro los que más la utilizan.

17. ¿Por qué medio conoció acerca de las plataformas tecnológicas o aplicativos móviles? Seleccione máximo dos respuestas.

- Redes sociales (Instagram, Facebook, WhatsApp; entre otras)

- Navegando en Internet.

- Correo electrónico.

- Voz a voz.

- Vallas Publicitarias.

- Televisión o radio.

- Todas las anteriores.

18. ¿Se encuentra suscrito a alguna plataforma tecnológica o aplicativo móvil, dónde se le informe acerca de promociones, actualizaciones, productos o modificaciones?

- Sí.

- No.

19. ¿Qué tipo de limitación ha encontrado al hacer uso de las plataformas tecnológicas o aplicativos móviles? Por favor mencione un solo aspecto.

20. Los inconvenientes más frecuentes a los que se ha enfrentado al hacer uso de plataformas tecnológicas o aplicativos móviles son: Seleccione máximo dos opciones. 
- Robo o perdida de objetos.

- Discusiones con el prestador del servicio.

- Pérdida de tiempo.

- Perdida de dinero.

- Ninguno.

- Otro

21. Seleccione según sus preferencias que le gustaría que mejoraran las plataformas tecnológicas o aplicativos móviles. Elija máximo tres opciones.

- Facilidad.

- Asequibilidad.

- Variedad de productos y servicios.

- Manejo de información personal.

- Asociaciones con otras marcas.

- Publicidad.

- Elección de bienes y servicios por preferencias.

- Cobertura en todas las zonas de la ciudad.

- Otra

\section{Datos demográficos.}

\section{Genero}

- Mujer.

- Hombre.

Edad

- 18 a 25 años.

- 26 a 32 años.

- 33 a 40 años.

- 41 a 60 años.

Estado civil

- Soltero.

- Casado.

- Unión Libre.

Ocupación

- Estudiante.

- Desempleado.

- Empleado.

- Independiente.

- Otro 